\title{
Teaching Design of Database Experiment Based on Constructivism
}

\author{
Nan Lin ${ }^{1, a,}$, Zhuoshi $\mathrm{Li}^{1, \mathrm{~b}}$ and Na Wang ${ }^{1, \mathrm{c}}$ \\ ${ }^{1}$ Computer Science Department, Information and Technology College, Jilin Agriculture University, \\ Xincheng Street, Changchun, 130118, China \\ a linnankitty@163.com, blzs036@126.com, 'c443953500@qq.com
}

Keywords: Constructivism, Scaffolding Instruction, Anchored Instruction.

Abstract: The advantage of constructivism based computer professional course is analysed in this paper. Based on constructivism, teaching theory and process of scaffolding instruction and anchored instruction are discussed. According to the characteristic of database experiment, teaching design and implementation are demonstrated by combining scaffolding instruction and anchored instruction. This teaching method has get good result.

\section{Introduction}

Constructivists think that learning is the process of knowledge construction. Knowledge can not be taught by teacher, it is obtained by the support of other people, including teacher and classmate, and by essential learning material under certain circumstance and society environment. Constructivism study can be concluded as four aspect. Firstly, learning is the process that the learner is initiative to construct his mental representation. It is affected by the old and new experiences. The result is not only including structured knowledge but also including non-structured knowledge and experience. Secondly, learning is in certain circumstance. Thirdly, Learner will construct his own understanding based on his original knowledge, which means different people will see the different aspect of the object. Fourthly, Learner should cooperate. The problem will be deeply understood by communication and inspiration ${ }^{[1,2]}$.

The traditional teacher centered teaching model, especially in the experiment teaching, is not as good as before especially in the experiment course any more nowadays. College students are more and more independent in innovation, especially in experimental classes. Constructivism learning theory holds that students are the subject of cognition. It promote the student centered learning under the guidance of teachers. In the constructivism learning environment, the teacher and students' function and role have some change. Experts in the field of educational technology have carried out a lot of research and exploration. They are trying to establish a set of constructivism learning theory and constructivism learning environment to adapt to the new teaching design theory and method in recent years. Although the establishment of this theoretical system is a difficult task, and can not be completed in the short term, its basic ideas and the main principles have become clear, and has begun to apply to guide the multimedia and internet based constructivism learning environment teaching design ${ }^{[3]}$.

\section{Teaching Method of Scaffolding Instruction and Anchored Instruction}

Teaching method of scaffolding instruction, anchored instruction and random access instruction 
are mature teaching method and developed under the constructivism teaching mode.

Scaffolding instruction is also known as "hawk teaching", which means that students are prepared to improve their learning ability by providing sufficient support when learning a new technique. Considering the computer experimental session, teacher should present the basic knowledge and software operation before students starting to use a new software. Students can only establish his own knowledge after guiding by teacher ${ }^{[4]}$. Cycle of scaffolding is shown in Figure 1.

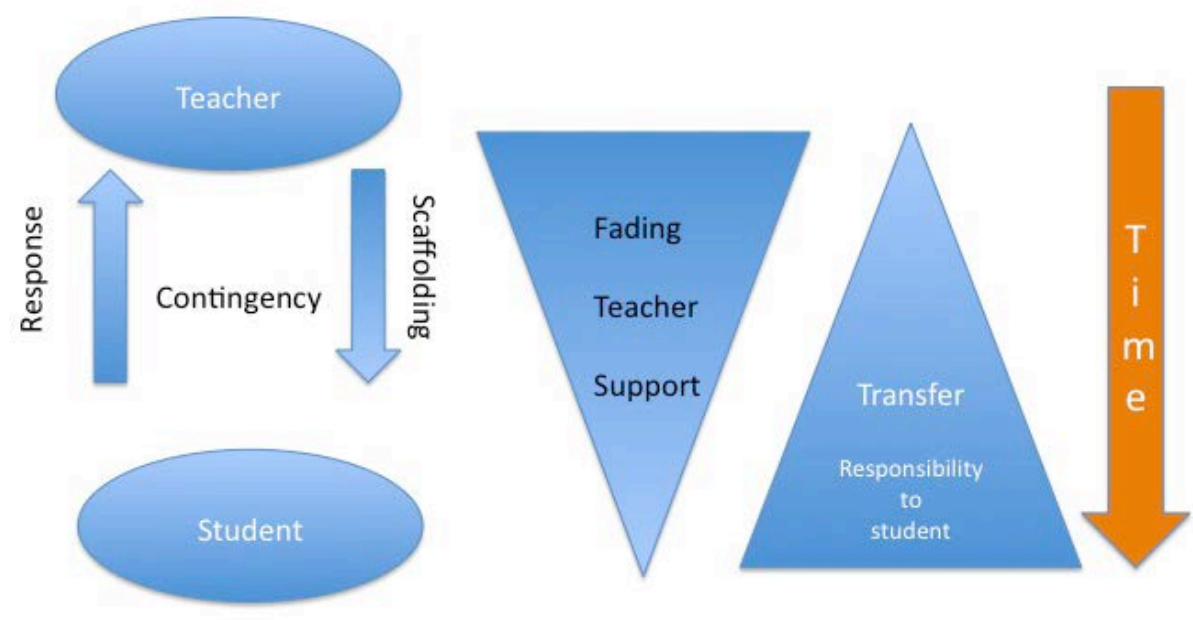

Figure 1 Cycle of Scaffolding.

Anchored instruction is also named "instance teaching" or "problem-based teaching”, which means teaching is based on real problem ${ }^{[5]}$. The following steps are used to govern the design of anchored instruction:

(1). Generating scenario which is the same or similar as the real situation.

(2). Confirming the problem according to the above scenario. Students choose the problem which is related to the current subject as their study content. The problem is the "anchor", and the anchor is dropped in this step.

(3). Learning by the students themselves instead of presenting by the teacher. Teacher gives some clue of the problem, and the student self-learning capability is developed.

(4). Cooperation by discussion and communication, students can understand the current problem deeply by discussing different view of points.

(5). Effectiveness evaluation can be directly reflected as the anchored instruction process is the problem solving process. No additional test is needed to evaluate effectiveness, students' performance can be observed and recorded during the anchored instruction process.

\section{Teaching Method of Scaffolding Instruction and Anchored Instruction}

According to the feature of database teaching, scaffolding instruction and anchored instruction can be combined.

1.5-hour database experimental "SQL Form Query" class will be shown as an example to explain the application of constructivism in database experimental teaching.

\subsection{Goal of the Database Experimental Class}

Student will understand the usage of query analyzer, master basic inquiry statement

\subsection{Students Study Status Analysis}

The class is provided to sophomore college student. It is the first time they know basic database 
theory, and it is difficult for them to understand the abstract concept of relationship model. Students have mastered database form creation and record input before the class, and they have some understanding of form. Now, SQL statement can be used in practice, which is helpful for the understanding of database theory in the class.

\subsection{Preparation before the Experimental Class}

This class should be in computer laboratory, and teacher can demonstrate the operating process by beamer. A database file, for example "Student Database", should be prepared before the class. Student form, class form, score form and so on should be included in the file, and all the instance should be filled in. It will save the time if students create and add instance in the class, and they can pay more attention on the key point of this class. The database file is stored in the laboratory public drive and students can download it to their experimental computer.

\subsection{Teaching Process Design}

(1). Teacher presenting the usage of query analyzer in teacher's computer. It will be demonstrated by beamer to the students.

[Idea of design] Students should master the environment of query statement, which means the basic operation of query analyzer, it is the foundation of the query experimental practice. This part is the basic operation of the software, and it is not easy for students to learn by themselves. It is recommended that teacher explain and demonstrate the operation, which means the teacher proved "scaffolding".

(2). Practice single SQL query statement.

Step 1, import. College will setup unified database management to record the score of all the students' classes. The question is, how can we find the data we would like to have from such a big score database? It is not advised to search one by one be because of it is lack of efficiency. SQL query statement can be used here to quickly search the required data.

[Idea of design] "Generating scenario", student is quite familiar with score for many years, and the score searching scenario is provided here. They will know how database will be used in daily life.

Step 2, setting up query task. Task: search for the students' number whose score is less than 60 in 00142 class.

[Idea of design] Search for the score is real instance regarding to students' study life, it can be considered as "anchor" here. The real problem is confirmed here, "anchor is dropped".

(3). Analysis inquiry requirement. In this scenario, students can be guided in the following way: what is the corresponding keyword for the output student number? What is the corresponding keyword in the score form? Is the relationship "and" or "or" in the two conditions in "where" statement? Meanwhile, SQL statement grammar should be noticed during practice, especially in the query analyzer, single quotation mark should be used for character type. Character type data should be considered in the practice. All the punctuation should use English half angle of symbols, for example, the single quotation mark.

[Idea of design] This part is fit for students' self-learning. Teacher will not tell the students which statement should be used for inquiry, instead, teacher should provide the clue how the problem should be solved, give the hint what is the key point to solve the problem, and make the students think by themselves. It is quite important here, student should learn by themselves with proper hint. Teacher should know how much the students have mastered, and according to the real situation, the teacher will decide how much the hint will be and how much the students can do by themselves.

(4). Students communication. Students can be divided to groups to discuss the problem and make 
try out on the computer. They can compare different methods and choose the best one inside them, which will be recorded in the experimental report.

[Idea of design] Creativity can be motivated, and problem can be deeply understand by discussion among the students. The whole learning process is "cooperation process".

(5). Check and review. Check and review the discussion of the students, the result of the computer experiment. Teacher can join the discussion, and answer the questions from the students.

[Idea of design] This is the end of the teaching process. It is evidence of the teaching result and it is also good experience which could be used in future. Effectiveness could be evaluated by the teaching process.

(2), (3), (4) can be used to carry out the task 2 and task 3 practice. E.g., task 2: query the student's name and number whose age is between 18 and 20 in student table, task 3: query the credit hours of database theory in class table.

Short summary after the experimental class: recording master status of the students, analysing improvement possibilities, and make summary of the class.

\section{Conclusions}

It is proved by experiment, theory can be understand easier by using multi-media and network and combining scaffolding instruction and anchored instruction of constructivism in database experiment teaching. Students are interested in dealing with real problems. They are willing to learn, think, and analyse. During this session, they improved their experimental capability and capability of dealing with problems.

\section{Acknowledgements}

2016 Jilin Agricultural University School-based special subject Operations Research study teaching model research and practice (project number: 2016JXZX22)

\section{References}

[1] Yan, Ren. (2009) Computer Class Design Based on Constructivism [J]. Newspaper of Taiyuan City Vocational College, 2009, 27-28.

[2] Weiwei Li.(2014) The visualization analysis of the hot spots and frontiers of Constructivism Teaching [J].Laboratory Research and Exploration, 2014, 33(5):148-151

[3] Yishu Luo, Shasha Qiang, Yaping Huang. (2007) Constructivism Based Teaching Mode Practice [J]. Computer Era, 2007, (8): 44-46.

[4] Xiaodong Xu. (2005) Computer Task Driven Teaching Mode Based on Constructivism [J]. Newspaper of Chongqing Technology College, 2005, (2):178-180.

[5] Mingren Zhao.(2011) Educational Research[J]. Analysis of Teachers' Learning from the Perspective of Constructivism,2011(2):83-86 